\title{
Investigation on the Effect of Linear Kinematic Hardening Model on Plasticity Prediction of Reciprocating Sliding Contact
}

\author{
M.Nagentrau ${ }^{1, a}$, W.A. Siswanto ${ }^{1, b}$, A.L.Mohd Tobi ${ }^{1, c}$ \\ ${ }^{1}$ Faculty of Mechanical and Manufacturing Engineering, Universiti Tun Hussein Onn Malaysia, \\ Batu Pahat, Malaysia \\ anagentrau.rau17@yahoo.com, bwaluyo@uthm.edu.my, ${ }^{\mathrm{c}}$ abdlatif@uthm.edu.my
}

Keywords: Ti-6Al-4V, Sliding, Cylinder on flat, Kinematic hardening.

\begin{abstract}
This paper discusses a finite element analysis of cylinder on flat contact configuration subjected to constant normal load and reciprocating tangential displacement with linear kinematic hardening models based on bi-modal Ti-6Al-4V cyclic stress-strain curves. The predicted evolution of plastic deformation such as the equivalent plastic strain, tangential plastic strain and shear plastic strain distributions on the contact region has been studied along with its respective predicted stress distributions. The effect of applied forward and backward sliding displacement movements on predicted stress and strain distributions have also been looked at. It is found that the stress distributions predicted for kinematic hardening model is similar for forward and backward movements while the predicted plastic strain distribution is increasing with reciprocating sliding movement. The predicted value keep increasing when it moves forward, backward and finally moves forward again. This is due to large strain effect of the model and its dependant on the displacement movement amount.
\end{abstract}

\section{Introduction}

Titanium alloy consider as an attractive material because of its characteristics of excellent corrosion resistance, formability, and fatigue resistance [1]. Study of sliding wear was conducted by many researchers by using different materials to identify the properties of friction and wear of sliding [2]. There are many researchers conduct study on sliding wear and plasticity of different materials. Basic term of plasticity is refers to the permanent deformation of a body under an acting force [3]. Soon the plastic deformation can cause accumulation of plastic strain which may result in wear [4]. Wear is considered as situation where it can cause major problems and big lost in the aspect of safety and maintenance.

Tribology is concerned as a branch mechanical engineering and materials science. Tribology is a term which derived from the Greek tribos where we can refer it as rubbing, "the science of rubbing" is the perfect literal translation for this term. [5]. Study of the interactions of sliding surfaces also included in this term. Many application of tribology are beneficial to mankind by making modern life possible. The word tribology was introduced or reported in a landmark report by Jost [6]. In addition, a progressive and continuous removal of material from a surface and a mechanical action causes deformation of material on a surface is defined as wear [7]. Fretting wear happens when the two contacting surfaces experience a small reciprocating slip not over $150 \mu \mathrm{m}$ [8] while, sliding wear is exceeds reciprocating slip over $150 \mu \mathrm{m}$.

Gross sliding condition also promotes plastic shearing across a wide region that leading to the accumulation of plastic strain, wear debris generation and delamination cracking [9]. Plasticity is the deformation of a material that having a non-reversible response or permanent changes to the applied force. The changes from elastic behavior to plastic behavior is called yield. Plastic properties are extremely varied, and depend both on the materials and the ambient conditions (temperature, the duration of the and etc) [3]. The elastic plastic stress strain response plays a pivotal role in the design and failure analyses of engineering components[10]. The law of evolution for the model comprises of a linear kinematic hardening component which describes the yield 
surface translation in stress space via the back stress, $\boldsymbol{\alpha}$ [11]. In addition this study will assist in predicting the stress and strain distribution which may lead to wear of materials. Thus, prevention steps can be carried out to increase the lifetime and efficiency of a material.

\section{Simulation Method}

\section{FE modeling}

Abaqus software is practiced in this study. The model that used is cylinder-on-flat configuration. The radius applied for the cylinder is $6.5 \mathrm{~mm}$ while for the flat plate the length, width and height elected as $100 \mathrm{~mm} \times 24 \mathrm{~mm} \times 8 \mathrm{~mm}$. The elastic properties of Ti-6Al-4V is obtained from [4] and plastic properties of the Ti-6Al-4V is obtained from [12] as shown in Table 1 and Table 2.

Fig. 1 shows the assembly module of FE model. Three element sets in order to assist in applying the parameters. The sets include Point load, Top and Bottom. The normal load, $P=2000 \mathrm{~N}$ was applied at the Point load while the Bottom was set to be constrained in $x$ and $y$-direction. The Top's set was been created in order to ensure all the nodes at the top of the half-cylinder moved according the applied displacement during the analysis.

Table 1: Linear cyclic plasticity hardening properties of Ti-6Al-4V [12]

\begin{tabular}{|c|c|}
\hline \multicolumn{2}{|c|}{ Cyclic plasticity properties of Ti-6Al-4V } \\
\hline Yield stress, $\sigma \mathrm{y}$ & $840 \mathrm{MPa}$ \\
\hline Hardening Modulus, c & $7.32 \mathrm{GPa}$ \\
\hline
\end{tabular}

Table 2: Elastic properties of Ti-6Al-4V [4]

\begin{tabular}{|c|c|}
\hline \multicolumn{2}{|c|}{ Elastic properties of Ti-6Al-4V } \\
\hline Young's modulus, $\mathrm{E}$ & $115 \mathrm{GPa}$ \\
\hline Poisson ratio, $\mathrm{v}$ & 0.342 \\
\hline
\end{tabular}

During the modeling, there were two types of surface that have been created in this model. There were master surface (cylinder contact surface) and slave surface (flat plate contact surface). Meanwhile the interaction properties was created by applying the Lagrange Multiplier contact algorithm in order to ensure the exact stick condition when the shear stress less than the critical shear value according to the friction law [13] and the coefficient of friction is set as 0.9. The equation's type of constraints were been used in order to ensure the top cylinder move uniformly horizontal and vertically together. After that four steps (including initial condition) that have been implemented during the FE modeling, where the first step is move to right, second step is move to left and third step is move to right again for the displacement of $0.2 \mathrm{~mm}$. The mesh module was applied on the FE model where the mesh of the contact area was been created by using Quadstructured in the mesh control as shown in Fig. 2 while the rest was been created by applying Quadfree-advanced in the mesh control. $50 \mu \mathrm{m}$ size of square mesh is applied at contact region while the coarse mesh is applied at further region in order to provide better prediction of plasticity and reduce the analysis computational time as the study just focusing on contact region. The model has been validated with previous research [4] and Hertzian theoretical solutions by using contact pressure (CPRESS) data. 


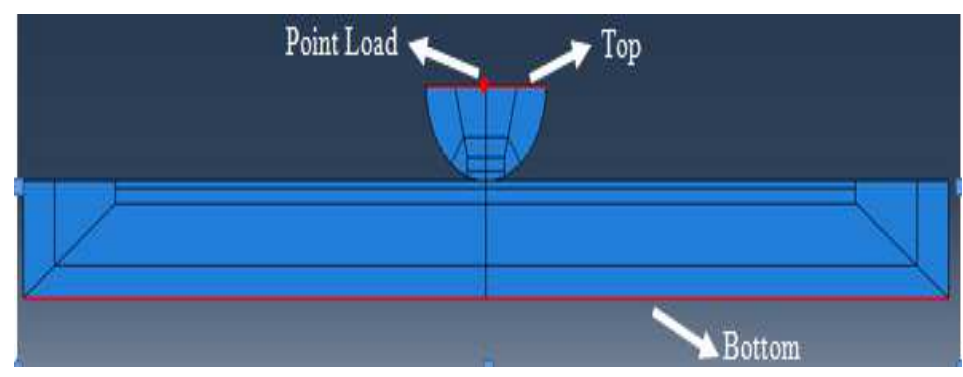

Fig. 1: The model assembly

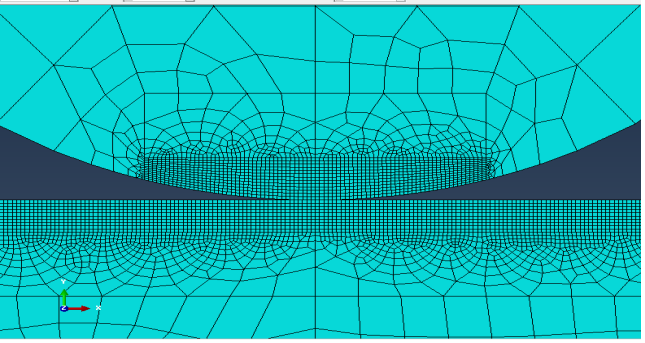

Fig. 2: Contact region mesh module

\section{Results and Discussion}

\section{The evolution of contact pressure analysis}

Fig. 3 shows the evolution of contact pressure (CPRESS) for linear kinematic hardening. The maximum value of the CPRESS is $750 \mathrm{MPa}$. In addition, CPRESS is maximum at the centre which validate with the Hertzian theoretical solution for contact pressure.

\section{The evolution plastic strain distributions}

Fig. 4 shows that evolution of equivalent plastic strain (PEEQ) for linear kinematic hardening plasticity. Obviously, PEEQ is higher at step 4 compared to step 3 and step 2. This is due to the accumulation of plasticity with sliding amount. The trend of the PEEQ graph for linear kinematic hardening model showing that there is not much increment of equivalent plastic strain (PEEQ) in step 4 compared with step 3.

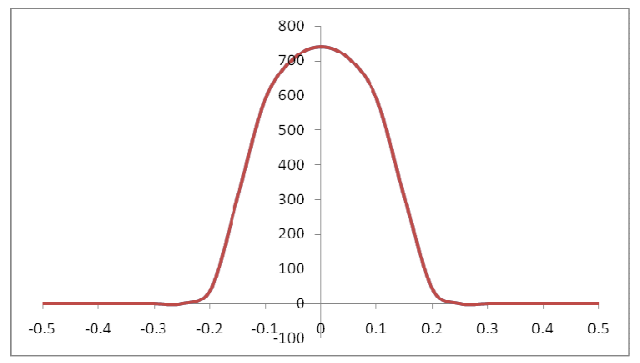

Fig. 3: Contact Pressure for linear kinematic hardening

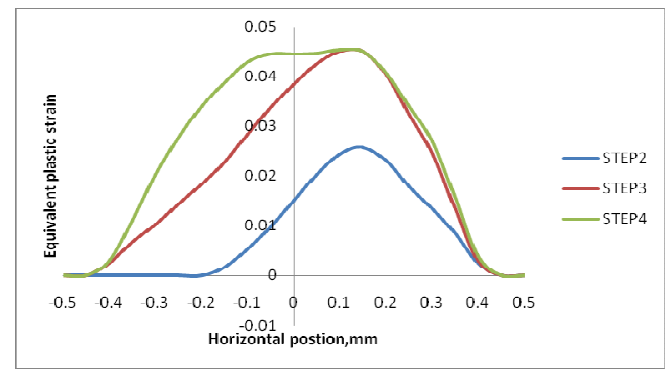

Fig. 4: Equivalent plastic strain of displacement

$0.2 \mathrm{~mm}$ for linear kinematic hardening

Fig. 5 shows that the evolution of tangential plastic strains (PE11). Based on the analysis it is clear that when the number of step increases more disturbance occurs at the curve of the graph where there are more ripples present in the step 4. In addition, the tangential plastics strain showing lower value if compared with the shear plastic strain in Fig. 6.

Fig. 6 shows that the evolution of shear plastic strain (PE12). Based on the analysis it is very obvious that the maximum shear strain takes place at step 2 for linear kinematic hardening model. Same as tangential plastic strain (PE11), the higher the displacement the higher the disturbance in the curve with more ripples, especially during step 4 . The shear plastic strain shows higher value if compared with the tangential plastic strain. 


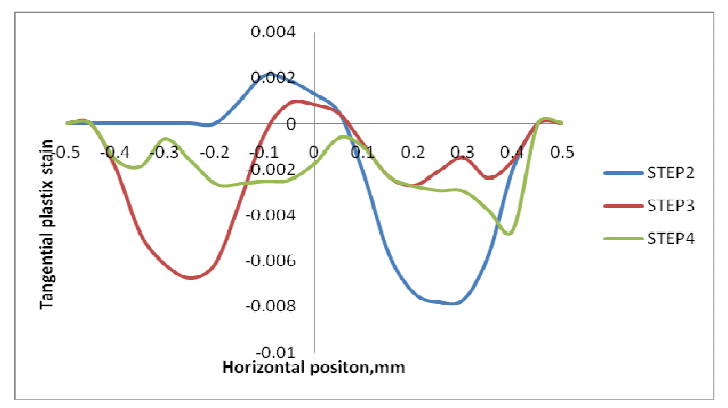

Fig. 5: Tangential plastic strain of displacement $0.2 \mathrm{~mm}$ for linear kinematic hardening

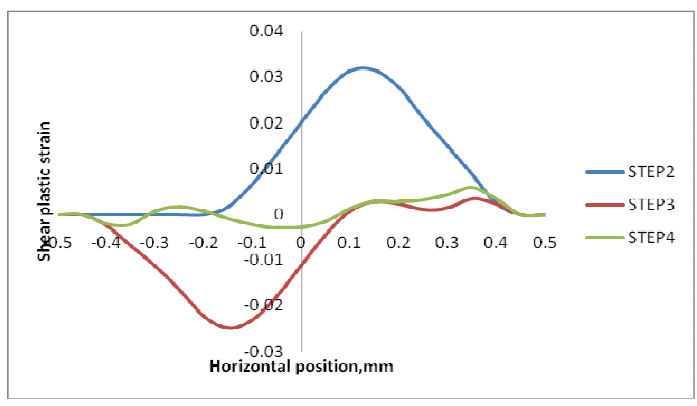

Fig. 6: Shear plastic strain of displacement $0.2 \mathrm{~mm}$ for linear kinematic hardening

\section{The evolution of distribution tangential stress and shear stress}

Fig. 7 shows tangential stress (S11) for all 3 different displacement movements which are step 2, 3 and 4 for linear kinematic plasticity hardening. The tangential stress predicted to be higher at the trailing edges compared to the leading edges of the contact area. The compressive stress predicted to occur at the leading edges while the tensile tangential stress is predicted to occur at the trailing edges. Basically, compressive tangential stress and tensile tangential stress of step 4 and step 2 almost similar. Step 3 looks like mirrored as the displacement is negative which the movement is from right to left. Moreover, the stress does not show much increment if compared with the strain graphs. Similar trends has also been predicted for shear stress (S12) in Fig. 8.

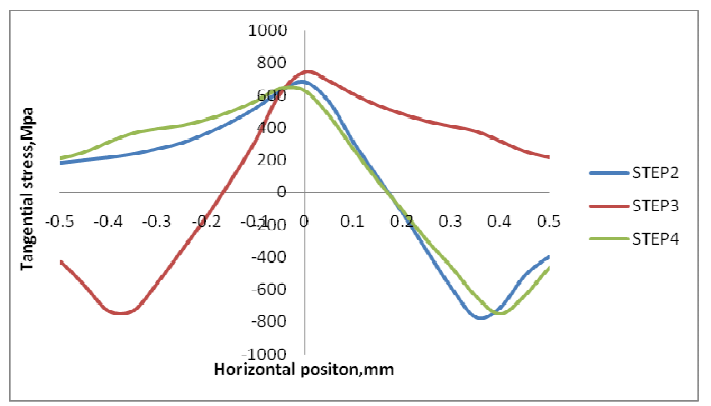

Fig. 7: Tangential stress of displacement 0.2 $\mathrm{mm}$ for linear kinematic hardening

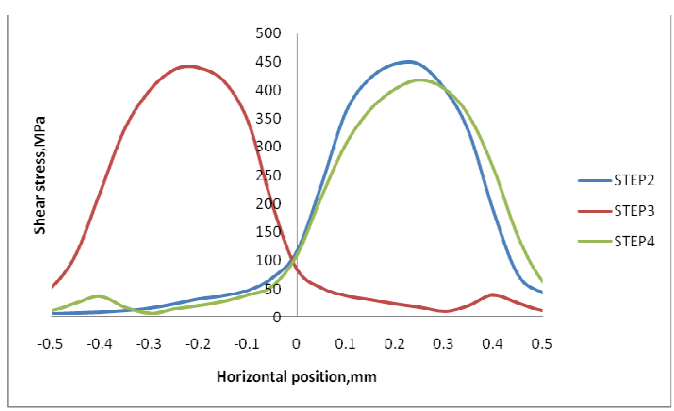

Fig. 8: Shear stress of displacement $0.2 \mathrm{~mm}$ for linear kinematic hardening

\section{Discussion}

Based on the results, it show that the value of equivalent plastic strain (PEEQ) increases as the number of step increases. This is due to the equivalent plastic strain (PEEQ) is calculated based on the summation of the tangential and shear plastic strain. Based on the strain results, the result of shear plastic strain is much more significant than the tangential plastic strain due to shear yielding effect of high frictional force.There are quite number of disturbance in both tangential and shear plastic strain graphs at Step 4 due to excessive amount of load and sliding steps movement where the flat plate might be stretched excessively and hardened on repeated sliding. But, when it moves to the side, the side is fresh thus, the new hardening is occurred and causes disturbance on the graphs. 


\section{Conclusion}

The main objective of this study is to investigate and predict the plasticity behavior on Ti-6Al-4V titanium alloy using finite element modeling on cylinder on flat surface due to sliding wear condition using linear kinematic hardening at $0.02 \mathrm{~mm}$ displacement. Obviously, the strain is more significant than stress in the prediction of plasticity. In addition, the strain distribution is increasing with step as the plastic strain value is depending on the sliding amount. Besides that, the formation of ripples in tangential and shear plastic strain graphs highly occurs at step 4 as the sliding amount is maximum compared with step 2 and 3 which results in higher disturbance due to stretching and hardening of material. Furthermore, the stress is does not affected much and not changing as it is predicted the stress is saturated.

\section{Acknowledgements}

The authors acknowledge the financial support by the Malaysian Ministry of Education and Universiti Tun Hussein Onn Malaysia (RESEARCH ACCULTURATION COLLABORATIVE EFFORT No. 1441).

\section{References}

[1] V. A. Joshi, Titanium Alloys (An Atlas of Structures and Fracture Features), CRC Press Taylor \& Francis Group, Florida, (2006) 7-15.

[2] I. I. Argatov, Asymptotic modeling of reciprocating sliding wear with application to local interwire contact, Wear, 271 (2011), 1147-1155.

[3] L.M. Kachanov, Fundamental of theory of plasticity, Amsterdam, north-Holland Pub Co., 1971, in series: North-Holland series in applied mathematics and mechanic ISBN 0-486-43583-0 (2004).

[4] A.L. Mohd Tobi, J. Ding, G. Bandak, S.B. Leen, P.H. Shipway, A study on the interaction between fretting wear and cyclic plasticity for Ti-6Al-4V, Wear, 267 (2009), pp. 270-282.

[5] B. Bhushan, Priciples and Applications of Tribology, John Wiley \& Sons, Inc., 1999.

[6] P.H. Jost, Committee on Tribology Report, (1966).

[7] E. Rabinowicz, Friction and Wear of Materials, 2nd Ed., Society of Tribologists and Lubrication Engineers (STLE), 840 Busse Highway Park Ridge, IL 60068-2302 USA, (1995).

[8] W.F. Gale, T.C. Totemeier, Smithells Metals Reference Book, 8th Ed., Elsevier ButterwirthHeinemann, 2004.

[9] L.M. Kachanov, Fundamental of theory of plasticity. Amsterdam, north-Holland Pub Co., 1971, in series: North-Holland series in applied mathematics and mechanic ISBN 0-486-43583-0, 2004.

[10]Y. Jiang, J. Zhang, Benchmark experiments and characteristic cyclic plasticity deformation. International Journal of Plasticity, 24 (2008), 1481-1515.

[11]Dassault Systemes, Abaqus Theory Manual. Version 6.10. RI, USA, 2010.

[12] M. Benedetti, V. Fontanari, The effect of bi-modal and lamellar microstructure of Ti-6Al-4V on the behavior of fatigue cracks emanating from edge notches, Fatigue Fracture of Engineering Materials Structures 27 (2004) 1073-1089.

[13]K.L. Johnson, Contact Mechanics, Cambridge University Press, Cambridge, 1985. 